\section{Characterizing Isozymes of Spanish Cherimoya Cultivars}

\author{
L. Pascual, F. Perfectti, M. Gutierrez', and A.M. Vargas ${ }^{1}$ \\ Departamento de Genética, Facultad de Ciencias, Universidad de Granada, \\ Granada 18071, Spain
}

Additional index words. Annona cherimola, cultivar identification, enzyme system

Abstract. Isozymes have been used as genetic markers to characterize seven Spanish cherimoya (Annona cherimola Mill.) cultivars. Fifteen enzyme systems were analyzed. Ten varied [aconitase (ACO, EC 4.2.1.3), alcohol dehydrogenase (ADH, EC 1.1.1.1), glutamate oxalacetate transaminase (GOT, EC 2.6.1.1), isocitrate dehydrogenase (IDH, EC 1.1.1.42), leucine aminopeptidase (LAP, EC 3.4.11.1), malate dehydrogenase (MDH, EC 1.1.1.37), phosphoglucose isomerase (PGI, EC 5.3.1.9), phosphoghtcomutase (PGM, EC 2.7.5.1), shikimate dehydrogenase (SKDH, EC 1.1.1.25), and triose phosphate isomerase (TPI, EC 5.3.1.1)] and five did not [acid phosphatase (ACPH, EC 3.1.3.2), diaphorase (DIA, EC 1.6.4.3), malic enzyme (ME, EC 1.1.1.40), 6-phosphogluconic dehydrogenase (6PGDH, EC 1.1.1.44), and superoxide dismutase (SOD, EC 1.15.1.1)]. Two cultivars, Campa and Campa Mejorada, had identical banding patterns for all enzymes tested. All others were identified as distinct cultivars because of isozyme differences. The identical isozyme profiles of 'Campa' and 'Campa Mejorada' probably indicate that they are the same cultivar. A cluster analysis of isozyme profiles showed that Spanish cultivars were clearly different from Californian cultivars.
Cherimoya $(2 \mathrm{n}=16)$ is a semi-deciduous fruit tree of Andean origin and is cultivated in several subtropical zones of the world. Spain is the world's most important producer, with plantations along the coastal strips of Málaga and Granada. These plantations are at altitudes ranging from sea level to $450 \mathrm{~m}$, with a mean annual temperature of $18 \mathrm{C}$ and a minimum that never falls below 5C. The climate is dry, with an annual rainfall of 350 to $600 \mathrm{~mm}$. two, 'Fino de Jete' and 'Campa', are extensively cultivated due to their superior quality and fruit yield. The other five cultivars are of less commercial importance and are sparsely distributed.

Isozymes are useful for identifying several fruit tree cultivars (Arulsekar and Parfitt, 1986; Cerezo et al., 1989; Jarret and Litz, 1986 Pontikis et al., 1980; Torres and Bergh, 1980; Weeden and Lamb, 1985). The objective of this research-was to characterize Spanish cherimoya cultivars using isozymes as genetic markers and to determine whether it was possible to distinguish individual cultivars. The increasing interest in cherimoya cultivation in various regions of the world has resulted in the proliferation of cultivars characterized prima-

Received for publication 11 Sept. 1992. Accepted for publication 26 Feb. 1993. This work has been supported by a project grant from the Comision Interministerial de Ciencia y Tecnologia. Progarama National de Investigation Agricola AGR89-0419. We thank J.M. Farre and J.M. Hermoso for providing the materials and for their scientific aid and advice. We thank N.C. Ellstrand and J.M. Lee for their critical review of the manuscript. The cost of publishing this paper was defrayed in part by the payment of page charges. Under postal regulations, this paper therefore must he hereby marked advertisement solely to indicate this fact.

'Departamento de Bioquímica y Biología Molecular.
Seven cultivars exist in Spain, but only rily by their morphological and pomological characteristics (Thomson, 1970). This fact, together with the unclear origin and relationship of most chenmoya cultivars used by breeders and the possibility that a cultivar may have different common names in different geographic locations, led us to compare isozyme banding patterns of Spanish cultivars with those of other commercially important Californian cultivars previously studied by Ellstrand and Lee (1987) and Lee and Ellstrand (1987). Among the 15 enzyme systems analyzed in this report, SOD, ACPH, DIA, LAP, $\mathrm{ME}$, and SKDH are reported for the first time in cherimoya.

Seven Spanish cherimoya cultivars were examined: 'Campa', 'Campa Mejorada' (improved 'Campa'), 'Fino de Jete', 'Manteca', 'Negrito', 'Pinchudo', and 'Piña'. At least two plants of each cultivar were assayed. The cultivars were grown in a field at the La Mayora Experimental Station, Consejo Superior de Investigaciones Científicas, Málaga, Spain.
Samples of young leaves and seeds from fruit self-fertilized by hand were studied. Seeds were used to analyze ADH and ACO, which were not expressed (ADH) or completely active (ACO) in leaves. Crude extracts were obtained using a homogenizer (Polytron; Kinematic, Luzern, Switzerland). Extracts were centrifuged at $4.000 \times \mathrm{g}$ and $4 \mathrm{C}$ for 20 min. The supernatant was used directly for electrophoresis or stored at $-80 \mathrm{C}$. Aliquots of the supernatant were loaded onto polyacrylamide gels or absorbed onto $6 \times 11-\mathrm{mm}$ Whatman filter paper wicks for horizontal starch gels. The extraction buffer used for the plant materials was $0.1 \mathrm{~mm}$ tris, $\mathrm{pH} 7.5$, including $12 \%$ polyvinylpirrolidone-40 (Soltis et al., 1983).

The compositions of the gels and buffer systems used for resolving the enzyme systems are indicated in Table 1. Polyacrylamide gels were run in a Mini-Protean system (BioRad, Richmond, Calif.) using manufacturerspecified conditions and stained for SOD according to Beauchamp and Fridovich (1971). After electrophoresis, starch gels (sliced horizontally) were stained as described by Soltis et al. (1983). The nomenclature adopted for the alleles and activity zones of the various enzyme systems follows those used by Ellstrand and Lee (1987). Loci encoding the least anodal isozyme for each enzyme system were numbered 1 , with additional loci numbered sequentially in order of increasing electrophoretic mobility. Similarly, allozymes at each locus were given numerical designations in order of increasing electrophoretic mobility. Lee and Ellstrand (1987) and Patty et al. (1988) established genetic control of activity zones for ACO, ADH, GOT, IDH, MDH, PGI, PGM, and TPI. We have studied the genetic control of the five newly described enzyme systems in Spanish cultivars by controlled crosses (Perfectti, 1992).

Of the 15 enzyme systems examined, five did not vary and were postulated to be encoded by a minimum of eight loci: Acph-2, Dia-1, Me-1, 6Pgdh-2, Sod-2, Sod-3, Sod-5, and Sod6 (Fig. 1). For 6PGDH, we observed only one well-defined monomorphic zone, which corresponds to the 6 Pgdh-2 locus reported by Lee and Ellstrand (1987). The least anodal zone corresponded to the polymorphic 6Pgdh- $110-$
Table 1. Electrophoretic buffer systems used to analyze cherimoya isozymes.

\begin{tabular}{|c|c|c|c|}
\hline Buffer systems & Gel matrix & Gel running conditions & Enzyme system $^{2}$ \\
\hline Tris-histidine & Starch, $10 \%$ & $50-\mathrm{mA}$ constant & $\begin{array}{l}\text { ACO, ACPH, } \\
\text { IDH, ME }\end{array}$ \\
\hline $\mathrm{LiOH}^{\mathrm{x}}$ & Starch, $10 \%$ & $175-V$ constant & $\begin{array}{l}\text { ADH, DIA, PGI, } \\
\text { PGM, SKDH } \\
\text { GOT, LAP, TPI }\end{array}$ \\
\hline Morpholine, $\mathrm{pH} 8.0^{\mathrm{w}}$ & Starch, $10 \%$ & 35-mA constant & MDH, 6PGDH \\
\hline Tris- $\mathrm{HCl}$ without $\mathrm{SDS}^{\mathrm{v}}$ & Polyacrilamide, $7.5 \%$ & $175-V$ constant & SOD \\
\hline
\end{tabular}

${ }^{2} \mathrm{ACO}=$ aconitase, $\mathrm{ACPH}=$ acid phosphatase, $\mathrm{IDH}=$ isocitrate dehydrogenase, $\mathrm{ME}=$ malic enzyme, $\mathrm{ADH}$ = alcohol dehydrogenase, DIA = diaphorase, $\mathrm{PGI}=$ phosphoglucose isomerase, $\mathrm{PGM}=$ phosphoglucomutase, $\mathrm{SKDH}=$ shikimate dehydrogenase, $\mathrm{GOT}=$ glutamate oxalacetate transaminase, $\mathrm{LAP}=$ leucine aminopeptidase, $\mathrm{TPI}=$ triose phosphate isomerase, $\mathrm{MDH}=$ malate dehydrogenase, $6 \mathrm{PGDH}=6-$ phosphogluconic dehydrogenase, $\mathrm{SOD}=$ superoxide dismutase.

y(Pitel and Cheliak, 1984).

x(Shields et al., 1983).

"(Lee and Ellstrand, 1987).

v(Laemmli, 1970). 


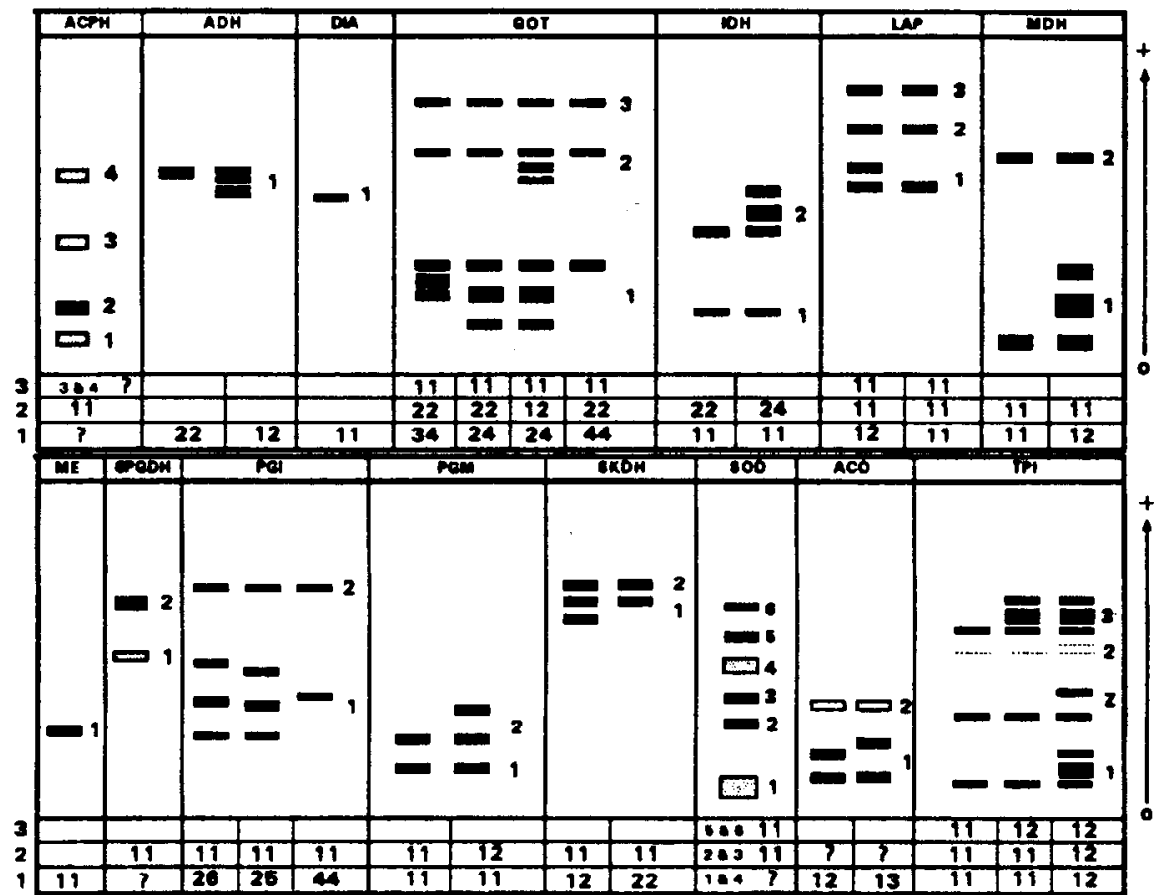

Fig. 1. Schematic illustrations of enzyme phenotypes for 15 enzyme systems in Spanish cherimoya cultivars. Stippled boxes represent weakly staining zones with poor resolution. Isozymes and their genotypes are shown for each enzyme system. Bands for the TPI-2 zone were lightly stained or absent.

cus mentioned by these authors, although it was evident in our material that it did not resolve clearly. Consequently, it was not used for the Spanish cultivar study nor for the comparative study among cultivars; thus, only 13 loci are listed (Table 2). Other poorly resolved activity zones for $\mathrm{ACPH}, \mathrm{ACO}$, and SOD (Fig. 1) also were not included in our study.

Polymorphism was observed in at least one activity zone in each of the remaining 10 enzyme systems. These enzymes systems were under the genetic control of 21 loci. Although three Aco loci have been described (Ellstrand and Lee, 1987; Lee and Ellstrand, 1987), in our material, we have detected only the two loci that are expressed solely in seeds: Ace- 1 and Ace-2. Ace-2 was not included in this work because it often did not resolve clearly. Our samples contained an additional anodal GOT zone, not described by Ellstrand and Lee (1987), which we designate Got-3 (Fig. 1). We interpret this invariant zone as being encoded by a monomorphic locus. TPI isozymes are the products of three loci: Tpi-1, Tpi-2 (detected weakly with overstaining), and Tpi-3. The
TPI-Z zone represents interlocus hybrid enzymes formed between the subunits encoded by the genes Tpi-1 and Tpi-2 (Patty et al., 1988). Additional alleles, described for some loci as Idh-2, Got-1, and Pgi-1 in Californian cultivars, are not among the Spanish cultivars.

Of the 29 loci analyzed, 16 were fixed for the same allele in all of the Spanish cultivars and 13 were polymorphic $(44.8 \%)$. Thirty alleles were detected at the polymorphic loci. Ten of these were minimally variable in that each locus had only two possible alleles. The remaining loci, Aco- 1 , Got- 1 , and Pgi- 1 , varied most in cultivars with three, three, and four alleles, respectively. 'Pinchudo' was the most heterozygous Spanish cultivar.

The variability observed in the enzyme systems was sufficient to identify all the Spanish cultivars except 'Campa' and 'Campa Mejorada'. These cultivars had the same enzyme profile for all the systems examined and also had similar morphological and physiological characteristics when grown in the same plantation and exposed to identical environmental influences. Consequently, 'Campa' and 'Campa Mejorada' likely are the same cultivar, or, less probably, 'Campa Mejorada' may be a 'Campa' seedling or a sport from a 'Campa' tree.

In our study, the Spanish cultivars were easily separated by analyzing only two enzyme systems (Table 2): GOT and TPI, GOT and IDH, or TPI and PGM. This separation will be useful and economical when identifying plant stocks for propagation. GOT and ACO alone may be used to identify the two most widely grown cultivars in Spain, 'Campa' and 'Fino de Jete'.

A comparative study was carried out to compare Californian and Spanish cultivars. Fourteen Californian cultivars described by Ellstrand and Lee (1987) and Lee and Ellstrand (1987) were compared with seven Spanish cultivars using the enzyme systems $\mathrm{ADH}$, GOT, IDH, MDH, 6PGDH, PGM, PGI, and TPI, all of which are common to our research and that of Ellstrand and Lee (1987). The degree of genetic similarity among cultivars was determined using the D-distance index of Nei (1972). AUPGMA (unweighted pair group method using arithmetic averages) dendrogram was constructed from the distance matrix by a computer program (Phylip 3.4) developed by Felsenstein (1991). This dendrogram is a clustering procedure and is not a true phylogenetic tree. In this dendrogram (Fig. 2), two major groups appear. The group including 'Booth' and 'Ott', among others, is characterized because all of the members are homozygous for allele 2 of the Adh- 1 and Tpi- 3 loci. Allele 1 of the Got-1 locus and allele 3 of the Got-2 locus are expressed exclusively in some cultivars of this group. The other group is divided into two subgroups. One, which includes all Spanish cultivars, is characterized by the high frequency of allele 4 of the Got- 1 and Pgi-1 loci. The second, which includes 'Bonita', 'Knight', 'White', and 'Spain', shows allele 6 of the Pgi-1 locus in all of the cultivars and allele 1 of the Idh-2 locus, which is not present in other groupings and is expressed in half of the cultivars.

All Spanish cultivars are similar and they differ from most Californian cultivars. Californian cultivars were more diverse, being distributed in all the groupings, probably due to their broad origins. Also, Spanish cultivars are clearly distinguishable, except for 'Campa' and 'Campa Mejorada'. These results could be important if using these cultivars in breeding programs. Identifying various cultivars is also an important step toward evaluating cherimoya germplasm.

Table 2. Genotypes for 13 variable loci in seven cherimoya cultivars.

\begin{tabular}{|c|c|c|c|c|c|c|c|c|c|c|c|c|c|}
\hline \multirow[b]{2}{*}{ Cultivar } & \multicolumn{13}{|c|}{ Variable loc1 } \\
\hline & Aco-1 & Adh-1 & Got-1 & Got-2 & Idh-2 & Lap-1 & Mdh-1 & Pgi-1 & Pgm-2 & Skdh-1 & Tpi-1 & Tpi-2 & Tpi-3 \\
\hline $\begin{array}{l}\text { Mejorada } \\
\text { Fino de }\end{array}$ & 12 & 12 & 34 & 22 & 22 & 12 & 11 & 44 & 11 & 12 & 11 & 11 & 12 \\
\hline Jete & 13 & 12 & 24 & 22 & 22 & 12 & 11 & 44 & 12 & 12 & 11 & 11 & 12 \\
\hline Manteca & 13 & 12 & 24 & 12 & 22 & 12 & 11 & 25 & 12 & 22 & 11 & 11 & 11 \\
\hline Negrito & 13 & 12 & 44 & 22 & 24 & 11 & 11 & 44 & 11 & 12 & 11 & 12 & 12 \\
\hline
\end{tabular}




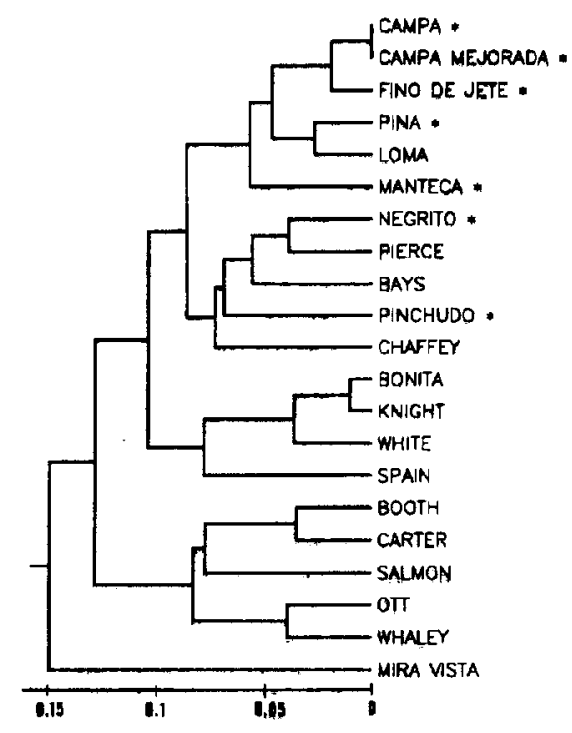

Fig, 2. Dendrogram showing the relationships among Spanish $\left(^{*}\right)$ and Californian cherimoya cultivars,

\section{Literature Cited}

Arulsekar, S. and D.E. Parfitt. 1986, Isozyme analysis procedures for stone fruits, almond, grape, walnut, pistachio and fig. HortScience 21:928937.

Beauchamp, C. and I. Fridovich. 1971. Localization of superoxide dismutase on polyyacrylamide gels. Anal. Biochem. 44:276-287.

Cerezo, M., R. Socias i Company, and P. Arus. 1989. Identification of almond cultivars by pollen isozymes. J. Amer. Soc. Hort. Sci. 114:164169.

Ellstrand, N.C. and J.M. Lee. 1987. Cultivar identification of cherimoya (Annona cherimola Mill.) using isozyme markers, Sci. Hort. 32:25-31.

Felsenstein, J. 1991. Phylip 3.4, Univ. of Washington.

Jarret, R.L. and R.E. Litz. 1986. Isozymes as genetic markers in bananas and plantains. Euphytica 35:539-549.

Laemmli, U.K. 1970. Cleavage of structural proteins during the assembly of the head of bacteriophage $\mathrm{T}_{4}$. Nature 222:680-685.

Lee, J.M. and N.C. Ellstrand. 1957. Inheritance and linkage of io zymes in the cherimoya. J. Hered. 78:383-387.

Nei, M. 1972. Genetic distances between populations. Amer. Naturalist 106:283-292.

Fatty, L. R., J.M. Lee, and N.C. Ellstrand. 1988. Interpretation of triose phosphate isomerase isozymes in the cherimoya (Annona cherimola Mill.). Biochem, Genet. 26:123-130.

Perfectti, F. 1992. Caracterización isoenzimática de cultivares de chirimoyo (Annona cherimola Mill,). MS Thesis, Univ. of Granada, Spain.

Pitel, J.A. and W.M. Cheliak. 1984. Effect of extraction buffers on characterization of isozymes from vegetative tissues of five conifer species. A user's manual. Can. For. Serv. Info. Rpt. PI-X. 34.

Pontikis, C. A., M. Loukas, and G. Kousounis. 1980. The use of biochemical markers to distinguish olive cultivars. J. Hort. Sci. 55:333-343.

Shields, C.R., T.J. Orton, and C.W. Stuber. 1983. An outline of general resource needs and procedures for electrophoretic separation of active enzymes from plant tissue, p, 443-468, In: S.D. Tanksley and T.J. Orton. (eds.). Isozymes in plant genetics and breeding. part A. Elsevier, Amsterdam.

Soltis, D. E., C.H. Haufler, D.C. Darrow, and G.J. Gastony. 1983. Starch gel electrophoreais of ferns: A compilation of grinding buffers, gel and elpctrode buffers, and staining schedules. Amer. Fern J. 734-27.

Thomson, P.H. 1970. The cherimoya in California. Calif. Rare Fruit Growers Yrbk. 2:20-34.

Torres, A.M. and B.O. Bergh. 1980. Fruit and leaf isozymes as genetic markers in avocado. J. Amer. Soc. Hort. Sci. 105:614-619.

Weeden, N.F. and R.C. Lamb. 1985. Identification of apple cultivars by isozyme phenotypes. J. Amer. Soc. Hort. Sci. 110:509-515. 